\title{
Burkholderia Postoperative Endophthalmitis and an Outbreak Including Bilateral Simultaneous Postoperative Endophthalmitis
}

\author{
Mike Yuan Chen ${ }^{1}$, Susan Ruyu $\mathbf{Q i}^{2}$, Jens Kratholm ${ }^{3}$ and Steve Arshinoff ${ }^{1,4 *}$ \\ ${ }^{1}$ York Finch Eye Associates, Toronto, Ontario, Canada \\ ${ }^{2}$ Department of Ophthalmology, Laval University, Quebec City, Canada \\ ${ }^{3}$ Narvik Eye Clinic, Narvik, Norway \\ ${ }^{4}$ Department of Ophthalmology and Vision Sciences, University of Toronto, Toronto, \\ Canada \\ *Corresponding Author: Steve Arshinoff, York Finch Eye Associates, Toronto, \\ Ontario, Canada.
}

Received: December 24, 2021

Published: January 31, 2022

(C) All rights are reserved by Steve Arshinoff., et al.

\section{Abstract}

Purpose: To describe a single-center series of the first Burkholderia contaminans postoperative endophthalmitis (POE) cases and the first suspected Burkholderia cepacia complex (Bcc) bilateral simultaneous postoperative endophthalmitis (BSPOE) in the context of Burkholderia bacteria and systemic Burkholderia infections.

Setting: The Narvik Eye Clinic, Narvik, Norway.

Design: Retrospective study of all 5 unilaterally and one bilaterally infected patients, the surgical environment, Burkholderia bacteriology and the likely cause of the infections.

Methods: Meticulous review of the case series occurring during unusual winter weather in arctic Norway in January 2019, detailed examination of the surgical clinic, dismantled for this assessment, followed by detailed review of the biology of Bcc species and the infections it can cause.

Results: Six patients developed postoperative Bcc endophthalmitis within 4 months postoperatively, with one case suffering BSPOE. All cases, except one eye of the BSPOE patient, were vitreous-culture positive for B. contaminans. The Bcc strain was genetically identical to the ones later cultured from the surgical center's ventilation system. All patients recovered visual acuity of $20 / 25$ or better after aggressive treatment.

Conclusions: Bcc-induced postoperative endophthalmitis is rare and can occur if operating room ventilation is tampered with. It is challenging to treat with generally poor outcomes prior to the current series, in which all cases did well.

Keywords: Endophthalmitis; Postoperative Endophthalmitis; Bilateral Endophthalmitis; Bilateral Simultaneous Postoperative Endophthalmitis; Bilateral Postoperative Endophthalmitis; Operating Room Ventilation; Burkholderia; Burkholderia Endophthalmitis

\section{Abbreviations}

Bcc: Burkholderia cepacia Complex; BSPOE: Bilateral Simultaneous Postoperative Endophthalmitis; CDVA: Corrected Distance Visual Acuity; DSBCS: Delayed Sequential Bilateral Cataract Surger- ies; ESCRS: European Society of Cataract and Refractive Surgeons; HEPA: High-efficiency Particulate Air Filter; IC: Intracameral; IOL: Intraocular Lens; iSBCS: International Society of Bilateral Cataract Surgeons; ISBCS: immediately sequential bilateral cataract surgery; 
LAF: Laminar Air Flow; POE: Postoperative Endophthalmitis; UCS: Unilateral Cataract Surgery; UNN/UNN-Tromsø: University Hospital of Northern Norway, Tromsø, Norway; VBNC: Viable But Nonculturable; WGS: Whole-genome Sequencing; YAG: Yttrium Aluminum Garnet

\section{Introduction}

Postoperative endophthalmitis (POE) is a rare, destructive complication of cataract surgery [1-3]. Recent advancements have significantly decreased POE rates and severity [4]. Gram-positive bacteria are the most common cause, but Gram-negatives, particularly Pseudomonas species, are associated with poorer outcomes [5-7]. The gram-negative, Burkholderia cepacia complex (Bcc), specifically Burkholderia contaminans, caused 5 unilateral and 1 bilateral simultaneous postoperative endophthalmitis (BSPOE) after unilateral (UCS) and immediately sequential bilateral cataract surgeries (ISBCS) in northern (arctic) Norway in January 2019 [8].

Below, we discuss the diagnosis, management, and the root cause of this episode in Norway, which implicated altered exterior ducting of the clinic's ventilation system. We then place this infection series into the context of Burkholderia infections; both ocular and systemic.

\section{Methods}

A detailed retrospective analysis of all patients diagnosed with Bcc-induced endophthalmitis following UCS and ISBCS between January $4^{\text {th }}$ and January $28^{\text {th }}, 2019$, at the private Narvik Eye Clinic in northern Norway was conducted. Thorough assessment of the surgical facility was performed. All details related to patients, surgeries, and treatments were confirmed with the operating surgeon (author JK) and from a recent publication by Lind., et al. describing their management and outcome after referral to the University Hospital of Northern Norway (UNN-Tromsø) [8]. PubMed and Google were searched for reports on Bcc infections and Bcc-induced POE. All related articles were carefully reviewed. Outcomes of the Narvik patients were compared to literature Bcc POE reports.

\section{Results}

Between January and April 2019, in Narvik, Norway, 7 cases of POE ( 1 bilateral +5 unilateral) were discovered in six patients after uneventful phacoemulsification and implantation of hydro- philic acrylic foldable intraocular lenses (IOLs) (B-Lens or BunnyLens AF, Hanita Lenses RCA Ltd., Kibbutz Hanita, Israel) by a single surgeon using intracameral (IC) cefuroxime prophylaxis following ESCRS recommended protocols. Two of the POE patients underwent UCS (left eyes) and 4 had ISBCS (BSPOE: 1, POE: 2 left, 1 right), totaling, 5 left and 2 right infections. Surgeries occurred on January $8^{\text {th }}, 13^{\text {th }}$ and $14^{\text {th }}, 2019$, with the right eye operated first in all 4 ISBCS cases. The surgeon routinely performed ISBCS since 2011 in accordance with the International Society of Bilateral Cataract Surgeons (iSBCS) "General Principles of Excellence in ISBCS 2009" (available at: https://itgo.ca/eyefoundationcanada/wp-content/uploads/sites/5/2020/05/2010-09-01-FINALISBCS-SBCS-suggestions-from-ESCRS-Barcelona.pdf).

Patients were seen on postoperative day one and at week one by the operating surgeon, with excellent vision and clear slit lamp examinations. On January $25^{\text {th }}, 2019,12$ days after surgery, two patients returned with reduced vision in their left eyes, without pain or redness. Case \#1 had undergone UCS, case \#2, ISBCS. Both had an inflammatory fibrin net on the anterior IOL surface with no flare, cells, or other alarming signs. The surgeon cleared the fibrin net with YAG laser, which immediately improved the patients' vision. Oral prednisone (50 mg) was prescribed with additional topical single use non-preserved dexamethasone $1 \mathrm{mg} / \mathrm{mL}$ drops $\left(\right.$ Monopex $^{\circledR}$, Thea Laboratories) hourly. Follow-up the next morning, January $26^{\text {th }}, 2019$, showed recurrence of the fibrin net with visual deterioration, followed by hypopyon later the same afternoon, in both patients. Suspecting POE, the patients were immediately referred to the University Hospital of Northern Norway (UNN)Troms $\varnothing$ for further testing and treatment. At UNN, vitreous taps were performed, and B. contaminans was detected in the vitreous culture of both cases 2 days later. Table 1 in the paper by Lind., et al. describes the treatment of all patients at UNN, and we agree with that table except for the exact dates of POE diagnoses and their omission of the second eye of case 3 [8].

A few days later, two more patients (Case \#3 post ISBCS and case $\# 4$, UCS) presented with similar symptoms in their left eyes and received the same diagnosis at UNN. Case \#5, having undergone ISBCS, presented one month later for the right eye. The last case, \#6, who underwent ISBCS, developed POE symptoms in the left eye four months after surgery. One day after admission for POE of the left eye at UNN, case \#3 developed severe inflammation with dramatic decline of vision to hand motion in right eye. He underwent 
bilateral vitrectomy with intravitreal administration of ceftazidime and gentamicin. Vitreous tap was positive for Bcc in only the left eye. The other 5 eyes had Bcc infection confirmed by positive vitreous culture or culture from the explanted IOL/capsular bag complex. All patients were treated with pars plana vitrectomy and multiple (except for the right eye of case \#3) regimens of intra- vitreal antibiotics. All except both eyes of case \#3, required IOL and total lens capsule explantation with subsequent iris-clip IOL implantation at a separate surgery once the infection had cleared [8]. All patients recovered final CDVA of 20/25 or better, improved from preoperative. These were the most successful outcomes of any Bcc endophthalmitis cases reported to date (Table 1).

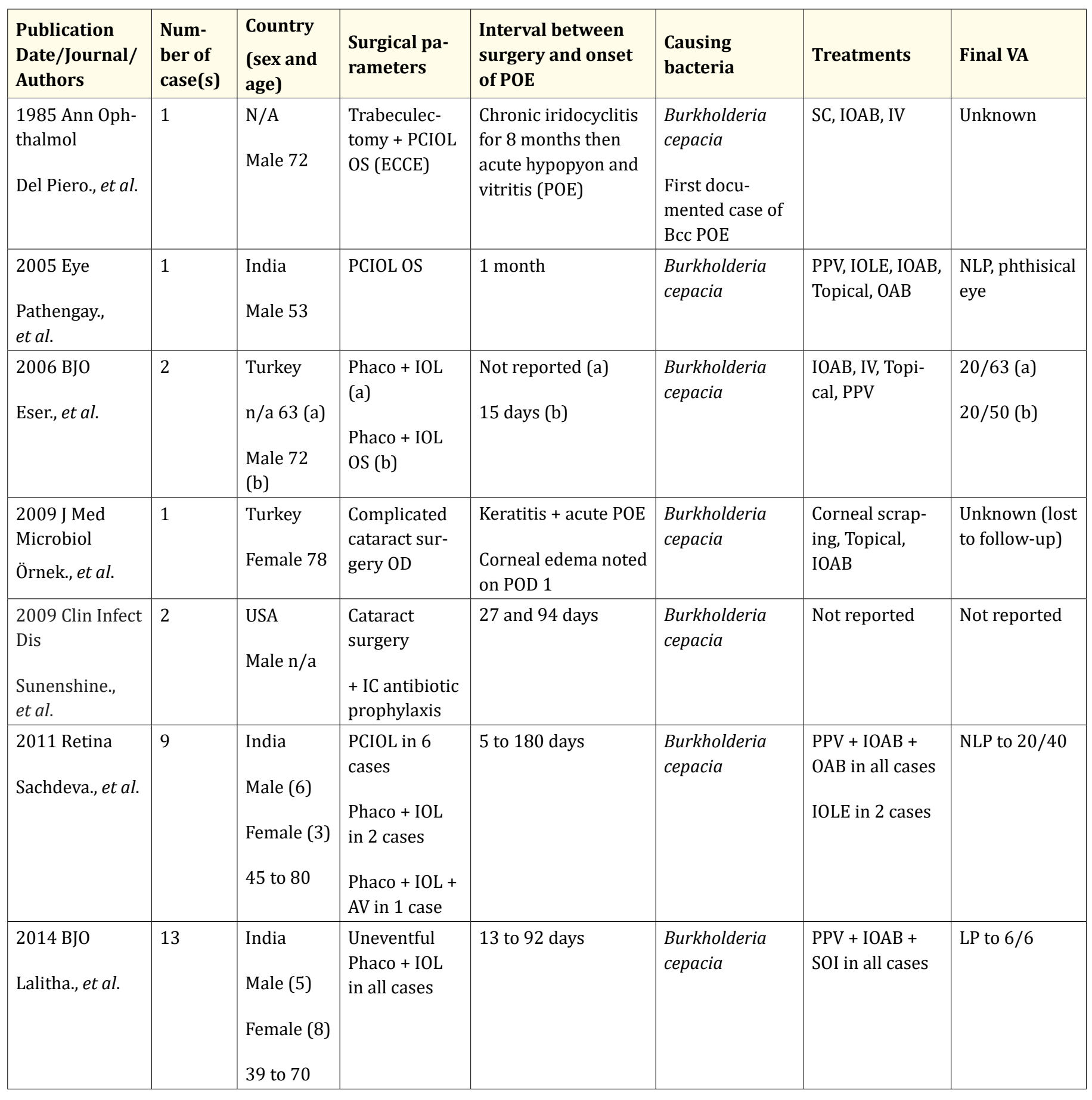

Citation: Steve Arshinoff., et al. "Burkholderia Postoperative Endophthalmitis and an Outbreak Including Bilateral Simultaneous Postoperative Endophthalmitis". Acta Scientific Ophthalmology 5.2 (2022): 43-52. 


\begin{tabular}{|c|c|c|c|c|c|c|c|}
\hline $\begin{array}{l}2018 \text { Int Oph- } \\
\text { thalmol } \\
\text { Mitra., et al. }\end{array}$ & 1 & $\begin{array}{l}\text { India } \\
\text { Female } 71\end{array}$ & $\begin{array}{l}\text { Uneventful } \\
\text { MSICS + IOL } \\
\text { OD }\end{array}$ & 1 month & $\begin{array}{l}\text { Polymicro- } \\
\text { bial: Burkhold- } \\
\text { eria cepacia } \\
\text { + Aeromonas } \\
\text { veronii }\end{array}$ & $\begin{array}{l}\text { IOAB + OAB + } \\
\text { IOLE + VD }\end{array}$ & $20 / 50$ \\
\hline $\begin{array}{l}2018 \text { JOVR } \\
\text { Deka., et al. }\end{array}$ & 3 & $\begin{array}{l}\text { India } \\
\text { Male (2) } \\
\text { Female (1) } \\
59 \text { to } 69\end{array}$ & $\begin{array}{l}\text { Phaco + IOL } \\
\text { in all cases }\end{array}$ & 14 to 21 days & $\begin{array}{l}\text { Burkholderia } \\
\text { cepacia }\end{array}$ & $\begin{array}{l}\text { IOAB in all cases } \\
\text { PPV in } 2 \text { cases }\end{array}$ & $\begin{array}{l}\text { NLP (phthisis } \\
\text { bulbi and } \\
\text { evisceration) } \\
\text { and } 20 / 30\end{array}$ \\
\hline $\begin{array}{l}2021 \text { JOII } \\
\text { Lind., et al. } \\
\text { (current series) }\end{array}$ & 6 & $\begin{array}{l}\text { Norway } \\
\text { Male (5) } \\
\text { Female (1) } \\
59 \text { to } 89\end{array}$ & $\begin{array}{l}\text { UCS }(2) \\
\text { ISBCS (4) } \\
\text { IC cefuroxime } \\
\text { prophylaxis in } \\
\text { all cases }\end{array}$ & 12 to 112 days & $\begin{array}{l}\begin{array}{l}\text { Burkholderia } \\
\text { contaminans }\end{array} \\
\begin{array}{l}\text { First B. contami- } \\
\text { nans POE cases }\end{array} \\
\begin{array}{l}\text { First Burkhold- } \\
\text { eria BSPOE }\end{array}\end{array}$ & $\begin{array}{l}\text { PPV + IOAB in } \\
\text { all cases } \\
\text { IOLE + TLCR in } \\
5 \text { cases }\end{array}$ & $\begin{array}{l}\geq 20 / 25 \text { for all } \\
\text { cases }\end{array}$ \\
\hline \multicolumn{8}{|c|}{$\begin{array}{l}\text { AV: Anterior Vitrectomy; Bcc: Burkholderia cepacia Complex; BSPOE: Bilateral Simultaneous Postoperative Endophthalmitis; ECCE: } \\
\text { Extracapsular Cataract Extraction; IC: Intracameral; IOAB: Intraocular Antibiotics; IOL: Intraocular Lens; IOLE: IOL Explantation; } \\
\text { ISBCS: Immediately Sequential Bilateral Cataract Surgery; IV; Intravenous; LP: light Perception; MSICS: Manual Small Incision Cataract } \\
\text { Surgery; NLP: No Light Perception; OAB: Oral Antibiotic; OD: Oculus Dexter (right eye); OS: Oculus Sinister (Left Eye); PCIOL: Poste- } \\
\text { rior Chamber Intraocular Lens; Phaco: Phacoemulsification; POD: Postoperative Day; POE: Postoperative Endophthalmitis; PPV: Pars } \\
\text { Plana Vitrectomy; SC: Subconjunctival; SOI: Silicone Oil Injection; TLCR: Total Lens Capsule Removal; UCS: Unilateral Cataract Surgery; } \\
\text { VA: Visual Acuity; VD: Vitreous Debulking. }\end{array}$} \\
\hline
\end{tabular}

Table 1: Summary of reported cases of Burkholderia POE reported cases following cataract surgery.

Additionally, a leukemic patient who underwent uneventful ISBCS in the Narvik Eye Clinic on Jan. 9, 2019, attended for followup 4 days later, Jan. 13, a day when multiple surgical patients later developed Burkholderia POE. Six weeks later (Feb 28, 2019) he was admitted to hospital in Thailand, with atypical pneumonia and pleural effusion, which did not grow any pathogen on culture, but Burkholderia are not tested for at that hospital. He had previously received multiple pneumococcal vaccines, and so was initially treated as Legionella pneumonia (airborne transmission) unsuccessfully. Treatment with the same medications used in Norway to successfully treat the Burkholderia cases, after consultation with the Narvik eye surgeon (author JK), resolved the pneumonia, suggesting that he had acquired airborne Burkholderia pneumonia at his Jan. 13 eye clinic visit.

Investigation of the POE cases was initiated by the surgeon JK on January $29^{\text {th }}, 2019$, immediately after identification of Burkholderia in the first two cases, by notification to the Health Governor of Northern Norway, Fylkeslegen i Nordland, and the Norwegian FDA/Helsetilsynet i Norge. The infection control team from UNNTromsø was instructed to investigate. On January $31^{\text {st }}$, and Febru- ary $22^{\text {nd }}$ of 2019 , this team collected bacteriological samples from all surfaces in the clinic operating room, and from 20 sterile singleuse devices employed during surgeries, on both visits. No Bcc was detected in any culture, but the ventilation system was ignored.

On February $23^{\text {rd }}, 2019$, copious flooding occurred in the clinic through the ventilation ducts. Suspecting a relationship between the ventilation and the recent outbreak, the surgeon collected water samples, and swabs from the ventilation ductwork, where a significant infestation of biofilm was evident (Figure 1 and Videos 1, $2,3)$. The samples were sent to the microbiology department of UNN-Troms $\emptyset$, but were never processed, as they were assessed to be irrelevant by the investigating team. Since Bcc can be difficult to culture, Dr. John J. LiPuma, a member of the International Burkholderia cepacia Working Group, at the US-Burkholderia repository was consulted by author JK and the samples were sent to him for analysis. The results were as follows:

- The isolates cultured from the ventilation system are confirmed as B. contaminans, a member of the Bcc family. 
- Genotyping analysis indicated that the isolates cultured from all patient samples are of the same strain.

- Whole-genome sequencing (WGS) was performed on 3 of the 7 Bcc isolates recovered from the ventilation samples, and kindly released by Professor P. Vandamme of Ghent University, Belgium. A near-perfect match at the DNA level was evident when comparing the WGS of the isolates from the ventilation samples with those from the vitreous cultures [28].

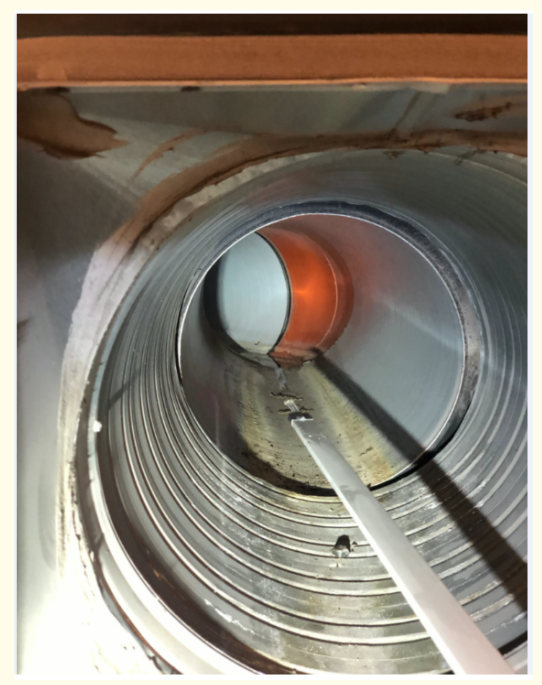

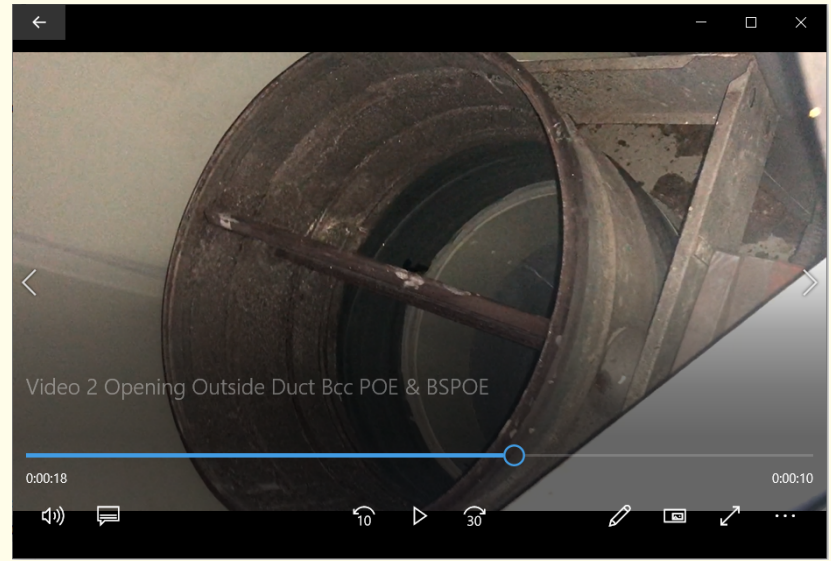

Video 2: Opening Outside Duct

Surgeon opening the ducts from outside in 2019.

Also available at http://www.vimeo.com/319196439

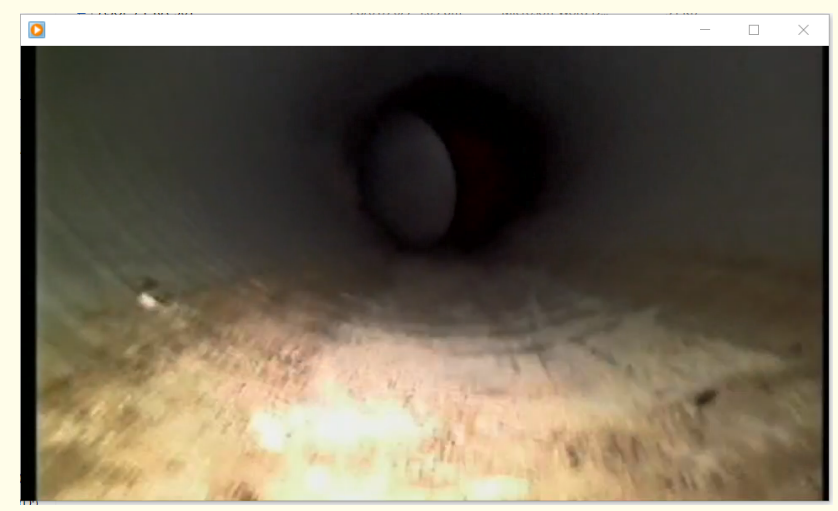

Video 3: Snaking Duct Oct 2019

Surgeon snaking interior of ductwork Oct. 21, 2019.

Also available at http://www.vimeo.com/367776459

\section{Discussion and Conclusion}

Unlike the other reported 8 cases of BSPOE reported over the past 50 years, the recent outbreak of Burkholderia POE from Norway has unique characteristics [7]. In contrast to most previous BSPOE cases iSBCS guidelines were closely adhered to in Narvik, including sterile preparation, instrumentation changes, and IC antibiotic prophylaxis. The infection source was airborne aerosolization from contaminated water infiltration into the altered ventilation system, a cause not previously encountered in previous BSPOE reports. This series was traced to $B$. contaminans, a member of the Bcc family not previously associated with endophthalmitis. Case 
\#3 is also the first reported case of Bcc BSPOE. The time to onset of POE, typical of Bcc-related endophthalmitis, is highly variable, presenting 12 days to 4 months postoperatively.

Initially named Pseudomonas cepacia, Burkholderia cepacia complex (Bcc), which includes Burkholderia contaminans, describes a group of gram-negative, slow-growing bataproteobacteria encompassing 24 closely related species of opportunistic pathogens [9]. Bcc contain complex genomes (6-9 Megabases) with three chromosomes engendering genotypic and phenotypic plasticity yielding rapid adaptation and mutation [9,10]. Burkholderia were named in honour of Walter Hagemeyer Burkholder, 18911983, professor of plant pathology at Cornell University, who first described B. cepacia (Latin - onion) in 1950 as the cause of bulb rot in onions [11].

Due to their oligotrophic metabolic requirements and low growth rate, Bcc survive and proliferate in nutrient-limited environments, hibernating when induced by starvation, in their "viable but nonculturable" (VBNC) state for months to years, allowing widespread distribution, even in distilled water and arctic soil, and making Bcc difficult to culture and identify [9,12-15]. Bcc is found in soil, lakes, rivers, drinking water, plant rhizospheres, and agricultural products globally [9].

Bcc are major contaminants of sterile and nonsterile pharmaceuticals and have compelled many recalls. They have caused numerous nosocomial outbreaks and can induce serious respiratory infections, particularly in patients with cystic fibrosis, chronic granulomatous diseases, immunodeficiency, infants, mechanically ventilated patients, and seniors. Bcc infected individuals may remain long-term asymptomatic carriers, sometimes progressing to rapid unexpected deterioration, culminating in fatal necrotizing pneumonia, termed "cepacia syndrome" [9].

Bcc are resistant to multiple antibiotics, including polymyxin, $\beta$-lactams, many fluoroquinolones, and trimethoprim [16]. Their ability to form biofilms, especially on plastic surfaces and metabolize certain antimicrobials as carbon sources complicates Bcc treatment, yielding unpredictable and variable outcomes [9]. B. cenocepacia and B. multivorans account for most Bcc infections in cystic fibrosis patients, whereas B. cepacia is the most prevalent species among non-cystic fibrosis patients [17]. Rarely, B. cepacia can also cause ophthalmic infections such as keratitis and POE $[18,19]$. To date, there have been at least 9 published reports of $B$. cepaciainduced POE after cataract surgery, mostly from India, but also USA and Turkey (Table 1). Oral ciprofloxacin, with excellent ocular penetration, has been found beneficial for Burkholderia POE [20-27].

Bcc is likely responsible for more ocular infections than reported due to widespread environmental distribution, and difficulties in culturing and identification. B. cepacia POE is generally difficult to treat, with variable outcomes despite aggressive treatments. Reported times between surgery and POE onset vary widely from 5 to 180 days [26]. Recurrent and persistent infections are common, partly due to the VBNC state, biofilm formation and Bcc multidrug resistance facilitated by a drug efflux system, inducible chromosomal $\beta$-lactamases and plasmid-mediated transfer of antibiotic resistance genes $[23,27]$.

Previous studies have found Bcc to have low susceptibility to the commonly used IC antibiotics, including cefuroxime (administered here - ESCRS protocol) and vancomycin, but is usually sensitive to ciprofloxacin $[20,22,24,29]$. Culture results in this series showed resistance to cefuroxime, with sensitivity to ceftazidime, ciprofloxacin, gentamicin and piperacillin/tazobactam, the last of which is generally effective against Bcc [8]. All patients recovered final corrected distance visual acuity of 20/25 or better, likely because Lind., et al. performed a "persistent and intensive treatment approach" with IOL explantation and total lens capsule removal (for all except both eyes of case 3) [8]. Nevertheless, all cases, except case \#3, required multiple re-administration of antibiotics with vitrectomies, perhaps due the ability of $B$. contaminans to colonize the IOL surface and lens capsule with VBNC biofilm formation [8].

Sources of POE infections can be challenging to trace. In this series, the initial routine surgical environment cultures taken by UNN failed to grow Bcc. Contamination of many perioperative and intraoperative products have been linked to Bcc-induced POE, such as saline solutions, irrigating fluid, trypan blue, ophthalmic viscosurgical devices, the internal fluid pathways of the phacoemulsification unit, a contaminated phacoemulsification handpiece and infected topical anesthetic eye drops [24]. In Narvik, the infection source was the ventilation system.

The Narvik Eye Clinic moved to its present location in 2006, 
when the surgeon purchased the surrounding land and building, which had been constructed during the second world war for the personal residence of a German general. The northern part of the building was renovated for an eye clinic and surgery, and a new ventilation system was installed by a certified engineering company. The outside air intake and exhaust ducts were made of galvanized steel, specifically approved for ventilation and resistant to Bcc growth, mounted well above the ground level for maintenance purposes and to prevent arctic dirt, rain, snow, and ice from entering the ductwork. The southern part of the building was not in good condition and so not used by the clinic. In 2012, the surgeon sold the southern part of the building to a construction company, which intended to build condominiums. The zoning bylaws permitted building on the footprint of the old building, but not beyond, as the surrounding land is protected forest. The construction company built a 12-condominium complex immediately adjacent to, and partly on top of, the Narvik Eye Clinic (Figure 2). Without informing the clinic, the builder, rebuilt the exterior air intake and exhaust ducts, which are now seen to be at ground level on the east (back) sidewall of the building (Figure 3). The two new ducts were found on investigation to each be composed of 15 alternating parts of orange angled wastewater tubes and white straight surface water tubes not designed for interconnection with a water-tight junction and not approved for ventilation. They were installed 2 meters underground, and therefore impossible to inspect and maintain throughout their length (Videos 1,2,3).

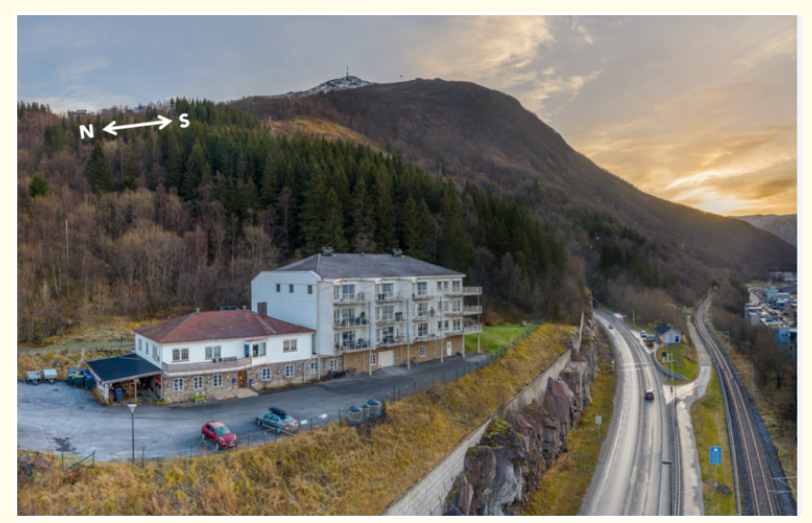

Figure 2: The Narvik Eye Clinic is on the ground floor of the older building to the north (left) of the larger condominium building.

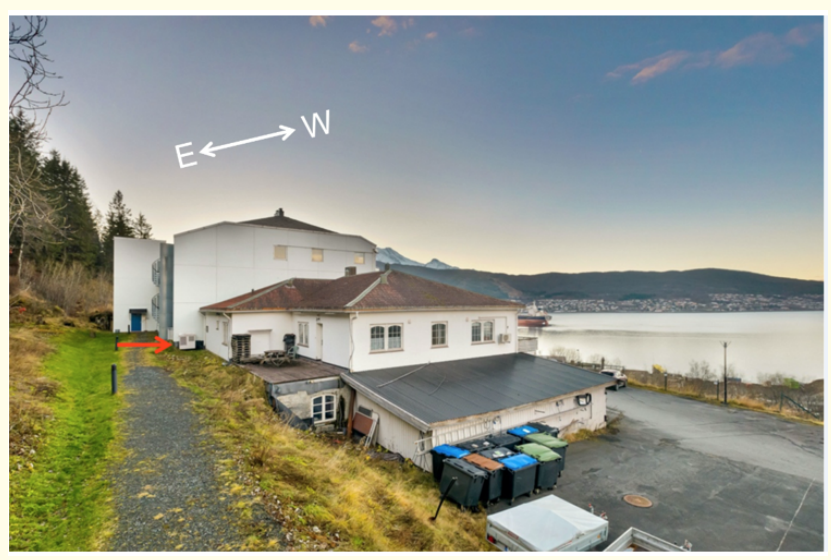

Figure 3: When the surgeon-owner sold the right to replace the southern part of the building (left), the builder chose to maximize the number of units by putting the new wall as close to the eye clinic building as possible, filling in the slope behind the clinic to create a walkway to the condominiums, and thereby burying the ventilation intake and outlet of the clinic. The new condominium was built on top of the southern 100 square feet of the clinic building and the ground floor of the condominium building made into a garage, while the ventilation to the operating room was reconstructed at ground level. (Red arrow shows the improperly reconstructed ventilation inlet-outlet).

The ventilation reconstruction was done during the arctic night from December $2^{\text {nd }}, 2011$, to January $10^{\text {th }}, 2012$, while the surgeon was away, and the clinic closed. This construction allowed groundwater and dirt to enter and accumulate within the ventilation system. Bcc are well known to thrive in diverse oligotrophic niches such as arctic soil and water and to construct biofilms, and almost certainly invaded the system with groundwater when the ventilation pipes were reconfigured and during subsequent seasonal freeze-thaws [9].

The endophthalmitis cases occurred seven years after the reconstruction. Norway annually allots 500 cataract surgeries per surgeon. The Narvik surgeon begins to operate in early January each year and continues until his allotment is reached, usually within the first few months. The surgical period corresponds to the coldest months of the year, with temperatures well below zero degrees Celsius, as Narvik is in the Arctic (latitude 68.43 degrees N). Thus, 
any infected water in the ventilation system is usually frozen, trapping Bcc at that time. During the later warmer months (May - November), when the water thaws, surgery was no longer performed. Therefore, the period of possible Bcc contamination never overlapped with scheduled surgeries. January 2019 brought unusually warm weather, with temperatures exceeding $10^{\circ}$ Celsius and gulf stream torrential rains causing an early thaw. Contaminated surface ground water entered the inadequately sealed ducts, and Bcc was blown into the operating room through the ventilation system, producing airborne contamination. As the ventilation system was destroyed by the flooding, it was not possible to completely reconstruct the scenario. However, water samples and biofilm swabs collected from the plastic ventilation ducts grew bacteria genetically identical to that of the vitreous and IOL/lens capsules explanted from all patients [28].

Multiple issues need to be considered to ensure appropriate asepsis during cataract surgery, including any changes to the operating facility. To ensure air quality, some hospitals and surgical clinics utilize laminar air flow (LAF) and high-efficiency particulate air filters (HEPA) [30]. The study of Sabherwal., et al. found no additional benefit of LAF and HEPA filters to control the incidence of postoperative endophthalmitis, perhaps due to the very low incidence of endophthalmitis from surgeries performed in scrupulously clean modern operating rooms in modern buildings [31]. In this series, LAF and HEPA filters may have avoided the ventilation system transmission of the infecting organisms [29,30].

It is interesting that the initial presentation of the infections to the operating surgeon was postoperative fibrin nets on the IOL surfaces. Senior author, SAA, was the first in the world to propose and use IC moxifloxacin prophylactically and has noted complete absence of postoperative fibrin nets in over 10,000 consecutive IC moxifloxacin cases. He has hypothesized that postoperative fibrin nets post adult cataract surgery in non-uveitic eyes are likely lowgrade POE, and when referred such cases manages them with topical moxifloxacin and prednisolone 1\% drops hourly instead of a YAG procedure. His small series of 6 cases resolved completely in a few days (unpublished data of author SAA). In retrospect, it is quite possible that postoperative fibrin nets are subclinical Bcc cases, which are likely more common than recognized, specifically given the ability of Bcc to form biofilms on plastic surfaces (such as IOLs).

Postoperative Bcc POE is rare and difficult to diagnose and treat. This study is the first reported series of B. contaminans en- dophthalmitis, including 1 suspected case of BSPOE. Surgeries were performed in accordance with all iSBCS recommendations, including prophylactic IC cefuroxime according to ESCRS protocol, but the infection source was environmental, the facility's altered ventilation system. These cases serve to emphasize one of the recommendations of the iSBCS General Principles of Excellence in ISBCS, 2009: "Nothing should be changed with respect to the operating room, surgical instruments, disposables or protocols without full consultation of the entire management, building, medical and nursing teams".

Like all studies, our paper has limitations and raises questions. This report of a case series of very unusual infectious origin, is instructional, not only because of the infectious source, which was initially ignored by the investigators, but also because these Burkholderia infected cases achieved a much better outcome than cases previously reported in the literature likely due to the "persistent and intensive treatment" provided by Lind., et al. Future studies should also look more carefully at postoperative fibrin, and its cause. Full understanding of Burkholderia endophthalmitis and its treatment will require detailed investigation of more than a single, albeit large, case series.

\section{Synopsis}

Burkholderia cepacia, a generally destructive rare cause of endophthalmitis, infected a series of 6 patients, 1 bilaterally, caused by alteration of the clinic ventilation system, but outcomes were excellent.

\section{Conflicts of Interest and Source of Funding}

None were declared for any author.

\section{What Was Known}

- Immediately sequential bilateral cataract surgery (ISBCS) offers many advantages over the traditional delayed sequential bilateral cataract surgery (DSBCS), however, the risk of bilateral simultaneous postoperative endophthalmitis (BSPOE) remains a significant concern.

- $\quad$ Burkholderia cepacia complex (Bcc)-induced POE is rare and can be challenging to treat and diagnose; contamination of various perioperative and intraoperative sterile products has been linked to Bcc-induced endophthalmitis. 


\section{What This Paper Adds}

- We recount the first case series of Burkholderia contaminans POE and the first reported case of BSPOE secondary to Bcc infection in the context of systemic Burkholderia infections.

- All potential issues must be carefully considered to ensure appropriate sterilization and asepsis during cataract surgery, including environmental factors such as the ventilation system. Improper reconstruction of the surgical facility ventilation system and resultant contamination were the root causes of POE infections in this study.

- Postoperative fibrin net on the intraocular lens surface after cataract surgery is rare and may indicate early infection.

\section{Acknowledgements}

The authors dedicate this paper to Douglas J. Mastel, owner of Mastel Precision Surgical Instruments, who encouraged and contributed to the investigation and reporting of these cases prior to his unexpected death on March 20, 2021, depriving ophthalmology of a leader, innovator, and thoughtful gentleman.

\section{Bibliography}

1. Malmin A., et al. "Twenty years of endophthalmitis: incidence, aetiology and clinical outcome". Acta Ophthalmology 99 (2021): e62-e69.

2. Nowak MS., et al. "Incidence and characteristics of endophthalmitis after cataract surgery in poland, during 2010-2015". International Journal of Environmental Research and Public Health 16 (2019): 2188.

3. Oh BL., et al. "Change in nationwide incidence of post-cataract surgery endophthalmitis: Korean cohort study from 2002 to 2013". Ocular Immunology and Inflammation 27 (2019): 756761.

4. Brundrett A., et al. "Current strategies for prevention and treatment of postoperative endophthalmitis". Current Ophthalmology Report 6 (201): 105-114.

5. Teweldemedhin M., et al. "Bacterial 8profile of ocular infections: a systematic review". BMC Ophthalmology 17 (2017): 212.

6. Stevenson LJ., et al. "Gram-negative endophthalmitis: a prospective study examining the microbiology, clinical associations and visual outcomes following infection". Clinical and Experimental Ophthalmology 48 (2020): 813-820.
7. Chen MY., et al. "Bilateral simultaneous postoperative endophthalmitis (BSPOE): Review of cases reported over the past 50 years". Journal of Cataract and Refractive Surgery (2021).

8. Lind C., et al. "Clinical course, treatment and visual outcome of an outbreak of Burkholderia contaminans endophthalmitis following cataract surgery". Journal of Ophthalmic Inflammation and Infection 11 (2021): 12.

9. Tavares M., et al. "Burkholderia cepacia complex bacteria: a feared contamination risk in water-based pharmaceutical products". Clinical Microbiology Review 33 (2020): e00139-19.

10. Dworkin M., et al. "The Prokaryotes". Volume 5 Proteobacteria: Alpha and Beta Subclasses (3rd ed.). Springer (2006): 15-18.

11. Burkholder WH. "Sour skin, a bacterial rot of onion bulbs". Phytopathology 40 (1950): 115-117.

12. Master ER and Mohn WW. "Psychrotolerant bacteria isolated from arctic soil that degrade polychlorinated biphenyls at low temperatures". Applied and Environmental Microbiology 64 (1998): 4823-4829.

13. Ahn Y., et al. "Oligotrophic media compared with a tryptic soy agar or broth for the recovery of Burkholderia cepacia complex from different storage semperatures and culture conditions". Journal of Microbiolog and Biotechnology 29 (2019): 1495-1505.

14. Fakruddin M., et al. "Viable but nonculturable bacteria: food safety and public health perspective". ISRN Microbiology 2013 (2013): 703813.

15. Li L., et al. "The importance of the viable but non-culturable state in human bacterial pathogens". Frontiers in Microbiology 5 (2014): 258.

16. Rhodes KA and Schweizer HP. "Antibiotic Resistance in Burkholderia Species". Drug Resistant Update 176 (2016): 82-90.

17. Spencer HK., et al. "An overview of the treatment of less common non-lactose-fermenting gram-negative bacteria". Pharmacotherapy 40 (2020): 936-951.

18. Levy JH and Katz HR. "Pseudomonas cepacia keratitis". Cornea 8 (1989): 67-71.

19. Del Piero E., et al. "Pseudomonas cepacia endophthalmitis". Annals of Ophthalmology 17 (1985): 753-756. 
20. Deka A., et al. "Burkholderia cepacia endophthalmitis: an unusual presentation". Journal of Ophthalmic and Vision Research 13 (2018): 504-507.

21. Eser I., et al. "Two cases of Burkholderia cepacia endophthalmitis". British Journal of Ophthalmology 90 (2006): 1211.

22. Pathengay A., et al. "Recurrent endophthalmitis caused by Burkholderia cepacian”. Eye (Lond) 19 (2005): 358-359.

23. Mitra S., et al. "Unusual microbiological presentations in polymicrobial post-operative endophthalmitis and their clinical correlations". International Ophthalmology 39 (2019): 21432148.

24. Lalitha P., et al. "Postoperative endophthalmitis due to Burkholderia cepacia complex from contaminated anaesthetic eye drops". British Journal of Ophthalmology 98 (2014): 14985102.

25. Sunenshine R., et al. "An outbreak of postoperative gram-negative bacterial endophthalmitis associated with contaminated trypan blue ophthalmic solution". Clinical Infectious Diseases 48 (2009): 1580-1583.

26. Sachdeva V., et al. "Burkholderia cepacia endophthalmitis: clinico-microbiologic profile and outcomes". Retina 31 (2011): 1801-1805.

27. Örnek K., et al. "Burkholderia cepacia keratitis with endophthalmitis". Journal of Medical Microbiology 58 (2009): 15171518.

28. Spilker T., et al. "Outbreak of Burkholderia contaminans endophthalmitis traced to a clinic ventilation system". Infection Control and Hospital Epidemiology (2021): 1-3.

29. ESCRS Endophthalmitis Study group. "Prophylaxis of postoperative endophthalmitis following cataract surgery: Results of the ESCRS multicenter study and identification of risk factors". Journal of Cataract and Refractive Surgery 33 (2007): 978-988.

30. Osher RH., et al. "Purifying the air over the operating field and reducing the possibility of airborne contamination with a new mobile laminar airflow device". Journal of Cataract and Refractive Surgery (2021).

31. Sabherwal S., et al. "Are high-efficiency particulate air (HEPA) filters and laminar air flow necessary in operating rooms to control acute post-operative endophthalmitis?" Indian Journal of Ophthalmology 68 (2020): 1120-1125.

\section{Assets from publication with us}

- Prompt Acknowledgement after receiving the article

- Thorough Double blinded peer review

- Rapid Publication

- Issue of Publication Certificate

- High visibility of your Published work

Website: www.actascientific.com/

Submit Article: www.actascientific.com/submission.php

Email us: editor@actascientific.com

Contact us: +919182824667 